\title{
A Learner based Perspective on STEM Learning in AP Courses
}

\author{
Albert Y. Bao ${ }^{1}$ \\ ${ }^{1}$ Dublin Jerome High School, Dublin, Ohio 43016, USA \\ * Correspondence: albertbao.2008@gmail.com
}

(Received: 02/18/2020; Accepted: 04/12/2020; Published: 04/15/2020)

DOI: https://doi.org/10.37906/isteamc.2020.5

\begin{abstract}
STEM fields are at the core of 21st Century Innovation. However only a small number of American students pursue STEM disciplines as their future careers. In high school, AP STEM courses provide unique opportunities to improve students' awareness, interests, and access to STEM learning in the school environment. A positive experience in these AP courses can be a catalyst to shaping a student's career interests and preferences towards STEM fields. However, these courses are also the most challenging among all high school curricula, and the situation is even more complicated by the shortage of teachers skilled in STEM subjects. It is then important to help students develop effective learning strategies for these courses. Through surveying high school students who have studied AP STEM courses, this study has found that students highly value learning physics with a concept-based approach, chemistry and calculus with a procedure-based strategy, and biology with a mix between memorization and concept. Additionally, students prepared best with a mix between concept-based activities, such as labs, and procedure-based activities, such as practice problems, in both physics and chemistry. Students who took biology found memorization-based preparations to be the most useful, and calculus was prepared best with procedure.
\end{abstract}

Keywords: STEM Learning, effective learning strategies, AP STEM Courses

\section{Introduction}

The question of how to educate the new generation of learners is one that has been asked for generations in the complex fields of science, technology, engineering, and mathematics, more commonly referred to as STEM. Especially in a time where teaching has become so homogeneous, where educators would use the same format of teaching for all their courses regardless of the topic, different courses have to be taught in different ways in order to ensure the best learning outcome for the student. Therefore, it is important to understand in what way each course is different, and to understand how students would learn best in each of the courses.

AP courses have been on the rise, with more than 2.8 million students taking the AP exams in 2018 alone (College Board, 2018). These courses have started to become a massive part of the education system, with more and more students recognizing its value each year. AP, which stands for Advanced Placement, is a program that allows students to take college level courses in high school. At the end of each year, an AP test can be taken that will represent the students' mastery in the course they take. According to College Board, the organization in charge of AP, "AP Exams are standardized exams designed to measure how 
well you've mastered the content and skills of a specific AP course" (College Board, 2020). Students who show mastery in the course and earn high scores on the exam will have their credits more recognized by colleges.

Research done in the field of STEM have shown that AP courses have a positive impact on the students' future careers. One study, conducted by Robinson, Fadali, Malisa, Johnson, and Batchman, found that taking AP courses in STEM early on in high school was a good way to prepare for university work in many STEM careers (Robinson et al., 2003). Many other studies also found evidence that support Robinson et al. For instance, Hargrove et al. concluded that students who pass and succeed AP exams "typically experience greater academic success in college" (Hargrove et al., 2008), whereas Kokkelenberg and Shinha showed that success in AP courses are significant indicators of academic preparation and ability (Kokkelenberg and Shinha, 2010). By taking AP STEM courses, students are preparing themselves for college and their future careers both by challenging themselves with learning more advanced material, but also by developing the skills necessary to overcome the challenge.

Furthermore, "students who take AP classes in calculus and the sciences are more likely to select majors in careers such as engineering, science, mathematics, and the medical field...both minority and nonminority students who were taking AP calculus and/or science courses in high school selected STEM careers at a higher rate than other careers" (Robinson et al., 2003). Not only are AP courses recognized for their high value in both education and experience, they also prove to help students gain insight and interest in the fields of the courses they took.

Overall, AP courses offer students more in both academic skill and interest, as is supported by Conger et al., stating that "we find suggestive evidence that taking an AP science course increases students' science skill and their interest in pursuing a STEM major in college." (Conger et al., 2019)

Studying AP courses is a valuable way of getting insight on how learners feel about each STEM topic. Major AP STEM courses include AP Physics 1/2/C, AP Calculus AB/BC, AP Chemistry, and AP Biology, which are the courses chosen for this study. Most importantly, it is studying from the learner's perspective that will give the most insight on how each course should be set up in a way that will ensure the best educational experience for them. Therefore, the overall goal of this study is to gauge at what students' value in each course, and use the results to interpret the ways to modify and improve the way the classes are taught.

The sample of the study is a group of high schoolers who have taken AP courses, with a sample size of 50 students total, divided evenly across the four subjects. Due to the relatively small sample size, the results may not be fully representative of the whole population of AP course takers. Error bars were included that were based off the standard deviation and the sample size of each variable in each subject.

\section{Methods}

The study has two parts. The first part measures how much each AP STEM course was weighted on its reliance on concept, memorization, and procedure. The second part measures the best way the students believed each course should be prepared.

For the first part, concept is defined as "understanding the meaning and mechanisms by which the procedure and material is based off". A course heavily based on concept is a course that requires students to understand the basic ideas and principles by which the topic works. Memorization is defined as "memorizing formulas, numbers, and overall material of the topic". A course heavily based on memorization would be a course where students would have to answer questions directly out of memory with little processing involved. Procedure is defined as where one would "plug in values into equations or 
follow a set of known steps to get to the answer". A course heavily based on procedure would be a course where students would answer questions by finding the right equation to use and plugging in given values in order to come to a solution.

To weigh each trait, a survey was made and filled out by students that either currently are taking or formerly took any of the AP STEM courses. The survey was formatted so a student would fill out, on a scale of one to ten, how much the course(s) they chose is reliant on each of the three traits.

A second part was added, which asked students what they thought the best way to prepare for each of the STEM courses was. The format is the same, asking the students to rate each category on a scale from one to ten. The categories are the same, being concept, memorization, and procedure, with slightly different definitions.

In this second part, concept is defined as "prepare by conducting and understanding experiments, readings, etc., in order to nail down the concept behind the material." Memorization is defined as "prepare by reading and memorizing the material." Procedure is defined as "prepare by doing things such as practice problems in order to get the procedure down."

The data for each part was then represented in a bar graph, with three bars each representing the averaged value earned for each of the three categories. The standard deviation was also calculated for each category.

Example of the question format are shown on the next page.

Question format for part one of the survey.

\section{AP Chemistry}

On a scale to 1 to 10,1 being the lowest and 10 being the highest, how much of chemistry do you think is based off each of the following

concept

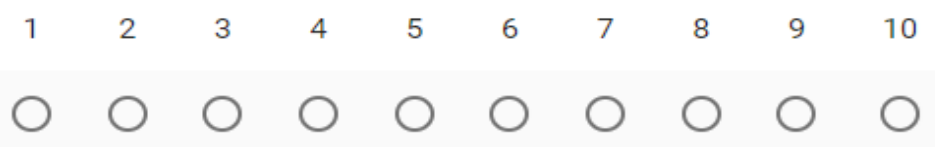

memorization

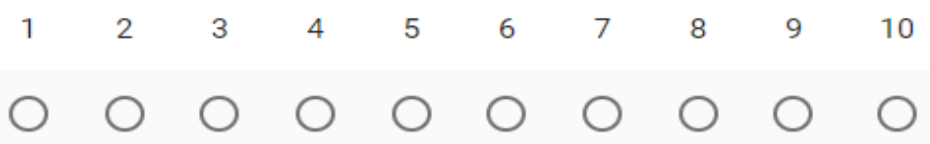

procedure

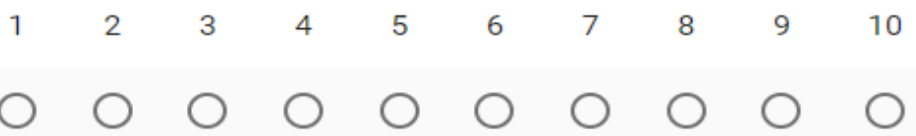




\section{AP Chemistry}

Question format for part two of the survey
On a scale from 1 to 10,1 being the worst and 10 being the best, which of the following will you believe is the best way to prepare for the class?

Prepare by conducting and understanding experiments, readings, etc, in order to nail down the concept behind the material.

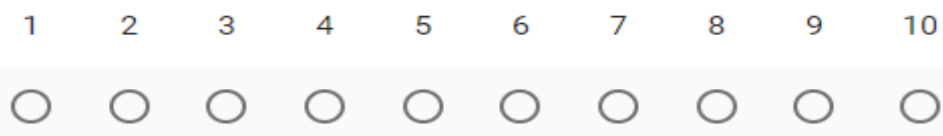

Prepare by reading and memorizing the material.

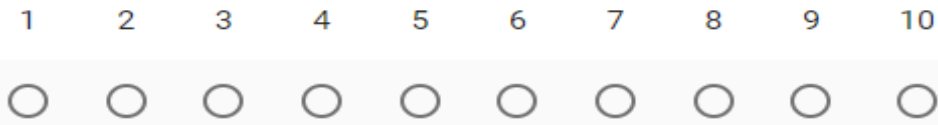

Prepare by doing things such as practice problems in order to get the procedure down.

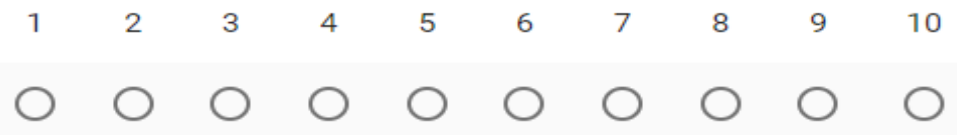

\section{Results}

Figure 1a-d Average part one results for the STEM courses' reliance on concept, memorization, and procedure (1a being physics, $1 \mathrm{~b}$ being chemistry, 1c being biology, and $1 \mathrm{~d}$ being calculus) based off a 50 student population

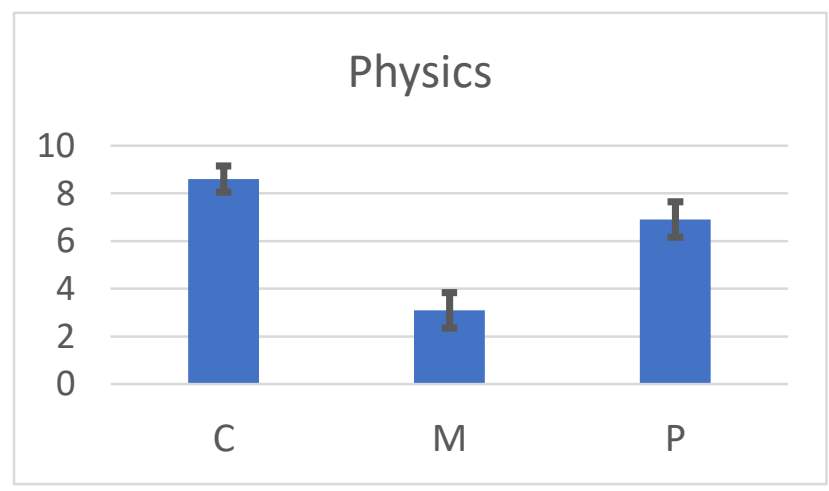

Physics has the highest score in concept, with a score of 8.6. The course also scored high in procedure but low in memorization. 


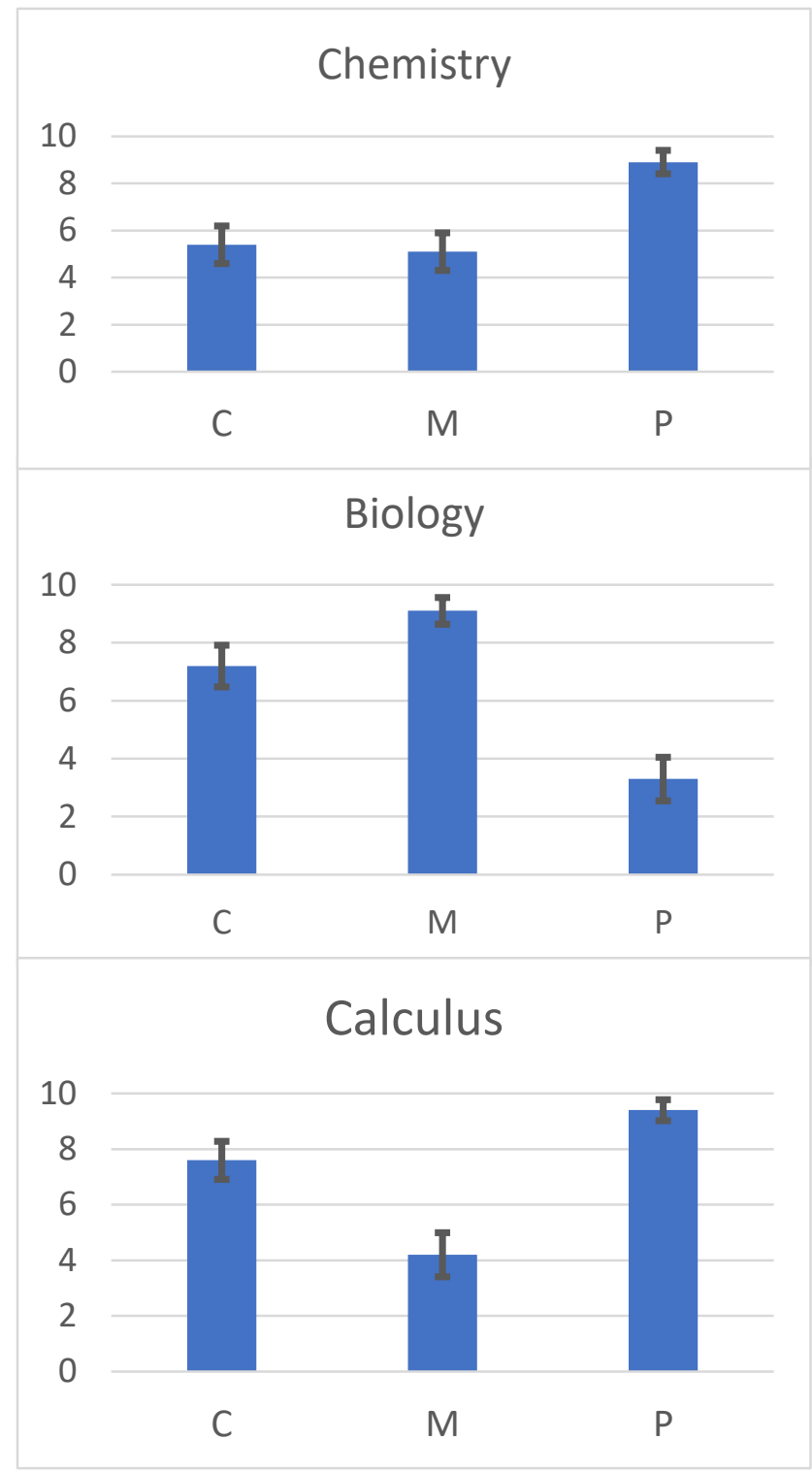

Chemistry scored the highest in procedure, with a score of 8.9. The course also got moderate values for both concept and memorization.

Biology scored the highest in memorization, with a score of 9.1. The course also got a moderately high score in concept but a low score in procedure.

Calculus scored the highest in procedure, with a score of 9.4. The course got a high score in concept and a moderate score in memorization.

Overall, the course with the highest score in concept was physics, the one with the highest in memorization was biology, and the one with the highest in procedure was calculus. 
Figure 2a-d Average part two results for the preparation of STEM courses weighted in concept, memorization, and procedure (1a being physics, $1 \mathrm{~b}$ being chemistry, 1c being biology, and 1d being calculus) based off a 50-student population

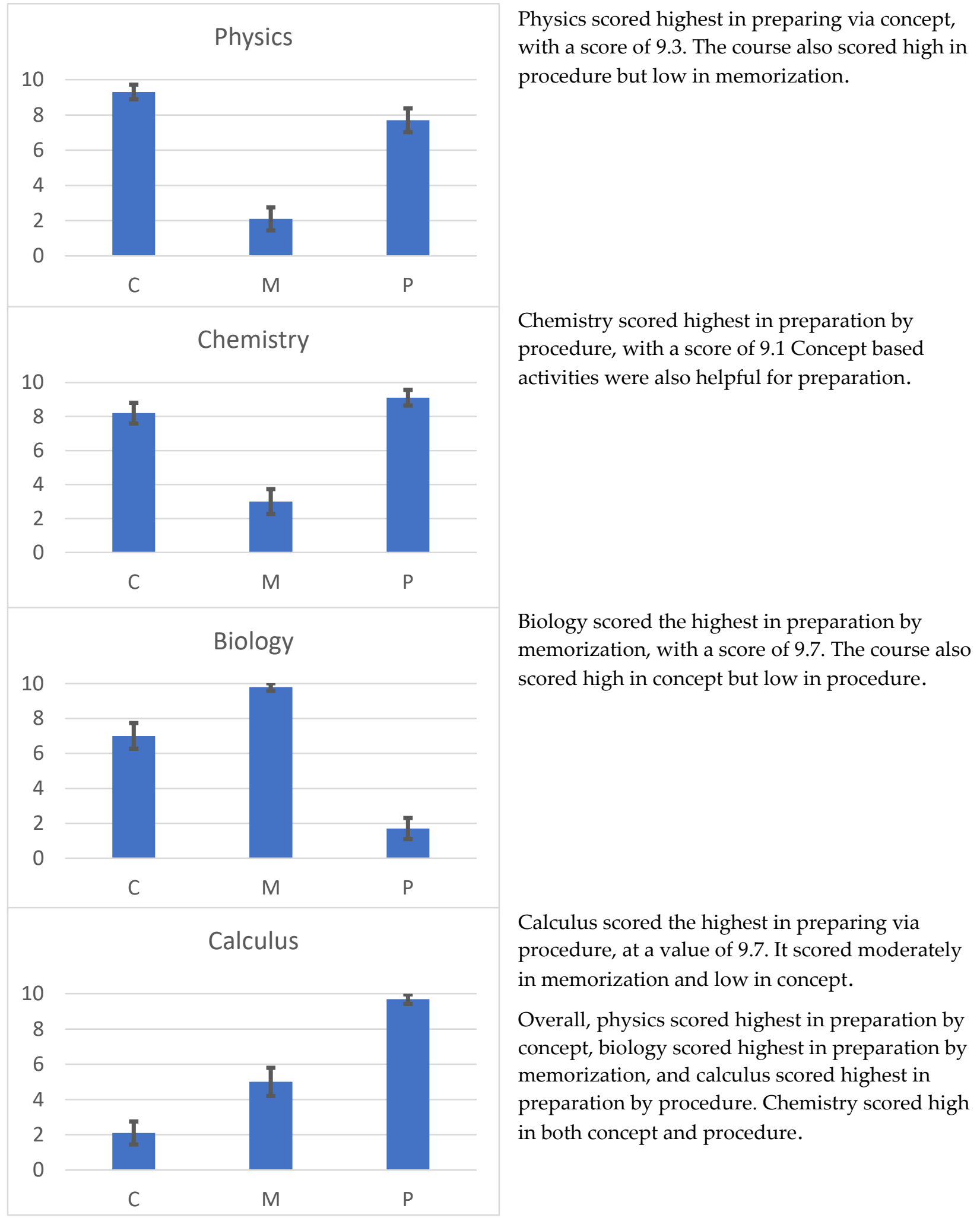




\section{Discussion}

The results for part one in physics show that students believe that learning concept is the most essential part of succeeding in the course. This makes sense, especially after seeing how physics scored low in memorization, as physics is too complex for one to memorize all the variations of problems that can stem from one concept. Therefore, knowing the concept and being able to apply it with procedure is the most important part of the course. Furthermore, the results for physics in the preparation part of the survey also support that physics is a heavily concept-reliant course. Students believed that learning through conceptbased activities, such as labs, was the most helpful to the students' preparation, next to doing practice problems in order to get used to the procedure. Memorization scored yet another low score in the course, as the most a student would need to memorize would be formulas and constants.

Chemistry scored highest in procedure in both parts of the study. Students believe that the course is especially reliant on knowing how to follow certain steps in order to obtain an answer, and to practice doing those steps to consistently do well. Chemistry, like physics, also is lowly based on memorization, and require the students to solve the problem on their own. However, unlike physics, chemistry generally requires the familiarity of procedure more, as it is harder for one to think their way out of a problem without a known procedure to follow. Concept in chemistry, although scoring moderately in the first part, scored quite high in the second. This is likely due to the many labs available for students to conduct, where the sense of the concept behind the lab was developed hands on.

Biology, unlike all the other courses, is the only one that scored consistently high in memorization for both parts of the survey. While the other courses require lots of problem solving with calculations and such, biology has very little, hence the low score in procedure for both parts. Students found that memorization was the best way to do well in the course, as almost all the questions require minimal processing, and only test whether the student knows a certain fact or not. Memorization, however, was not the only thing that helped students learn. Concept obtained moderately high scores for both parts as well. Students likely found it easier to memorize and apply their knowledge onto questions if they understood the concept behind it. Additionally, labs are common in biology, allowing students to develop a higher level of understanding of the concepts present. Lastly, procedure scored low for both parts, as the questions are formatted in a way where the student either knows it or doesn't, where there is no procedure involved, and therefore no procedure to practice.

Calculus obtained the highest score in procedure for both parts. As the questions present in calculus are very much based off how well one can manipulate the problem in a way that would allow them to use known equations and steps, procedure is essential. And in order to do the procedure successfully, students found that practice made the biggest impact. The course was also found to be quite reliant on concept, as the students found that if they understood the concept behind the material of the class, it would be easier to memorize the equations and steps or possibly even derive them themselves. However, concept scored very low in the second part of the survey. This is most likely due to the fact that there are very limited experiments and other concept-based activities that can be conducted in calculus. Finally, memorization scored moderately low in both parts as the only thing memory based that would help students succeed would be to memorize equations and constants.

\section{Conclusion}

Being able to understand what students' value and find helpful is a useful indicator of what can and should be improved in classrooms. Courses that score high in concept in part one would want to center their teaching more on understanding the "why" behind the material the students are learning. With the 
results in part two, students believe that they prepare and learn best with the implementation of more labs or activities that will help them get experience in what any of the formulas or such learned in class actually mean in the real world. High scores in memorization for either part show that the best way to help students in the course would be to improve memorization techniques, such as flashcards. Lastly, courses who scored highly in procedure may find that sufficient examples and practice problems will help improve the students in their learning.

\section{References:}

College Board. (2018). AP Program Participation and Performance Data 2018 Summary Report. Retrieved April 11, 2020, from https://secure-

media.collegeboard.org/digitalServices/pdf/research/2018/Program-Summary-Report-2018.pdf

College Board. (2020). About AP Exams. Retrieved April 11, 2020, from

https://apstudents.collegeboard.org/about-ap-exams

Conger, D., Kennedy, A., Long, M., \& McGhee, R. (2019). The Effect of Advanced Placement Science on Students' Skills, Confidence and Stress. The Journal of Human Resources. Retrieved from http://jhr.uwpress.org/content/early/2019/06/03/jhr.56.1.0118-9298R3.abstract

Hargrove, L., Godin, D., \& Barbara, D. (2008). College Outcomes Comparisons by AP and Non-AP High School Experiences. College Board Research Report, 2008-3. Retrieved from http://www.schoolinfosystem.org/pdf/2009/01/08-1574_CollegeOutcomes.pdf

Kokkelenberg, E., \& Sinha, E. (2010). Who succeeds in STEM studies? An analysis of Binghamton University undergraduate students. Economics of Educational Review, 29(6). Retrieved from https://www.sciencedirect.com/science/article/abs/pii/S0272775710000816

Robinson, M. (2003). Student enrollment in high school AP sciences and calculus: How does it correlate with STEM careers? Bulletin of Science, Technology \& Society. Retrieved from https://journals.sagepub.com/doi/abs/10.1177/0270467603256090

Robinson, M., Fadali, M., Malisa, M., Johnson, W., \& Batchman, T. (2003). AP Mathematics and Science Courses as a Gateway to Careers in Engineering. ASEE/IEEE Frontiers in Education Conference. Retrieved from https://journals.sagepub.com/doi/abs/10.1177/0270467603256090 